\title{
DIÁLOGOS SUCESSIVOS E ENSINO POR PROJETO: ANÁLISE COMPARATIVA DE ESTRATÉGIAS DE ENSINO NAS AULAS DE LÍNGUA INGLESA
}

\author{
Successive dialogues and teaching by project: comparative analysis of teaching \\ strategies in english classes
}

Letícia Maria dos Santos Grangeiro - IFAP/Brasil José Claudio Del Pino - UNIVATES/Brasil Marli Teresinha Quartieri - UNIVATES/Brasil Miriam Inês Marchi- UNIVATES/Brasil

Resumo: O presente estudo trata da utilização das estratégias de ensino Diálogos Sucessivos e Ensino por Projetos, fazendo uma análise comparativa e apresentando os resultados e impressões obtidas em cada uma delas. Tais estratégias foram desenvolvidas no Instituto Federal do Amapá, campus Santana, envolvendo a turma de $1^{\circ}$ ano do ensino médio integrado ao técnico do curso de Comercio Exterior. As estratégias foram aplicadas em momentos distintos no decorrer do primeiro semestre do ano de 2017, apontando resultados significativos, principalmente, no que diz respeito a interação social e acadêmica com os alunos e professores e como essa interação pode impactar nos demais ramos da vida escolar do educando. A utilização das estratégias são formas de envolver os alunos em disciplinas que, muitas vezes, consideram menos atraentes, com o objetivo de modificar a percepção da turma sobre determinado conteúdo, que pode ser considerado difícil e acaba por se tornar um mero decorar de fórmulas e conceitos.

Palavras-chave: Língua Inglesa. Estratégias de Ensino. Diálogos Sucessivos. Ensino por Projetos.

Abstract: The present study deals with the use of successive Dialogues and Teaching by Projects strategies, making a comparative analysis and presenting the results and impressions obtained in each of them, that took place in the Federal Institute of Amapá, Campus Santana, involving the class of 1st year of the high school integrated to the technician of the course of Foreign Trade. Strategies were applied at different times during the first half of 2017, pointing out significant results, mainly regarding social and academic interaction with students and teachers, and how this interaction may impact on other branches of school life teaching. The use of strategies are ways to involve students in subjects they often find less attractive, with the aim of modifying the perception of the class about certain content, which can be considered difficult and ends up becoming a decoration of formulas and concepts.

Keywords: English, Teaching Strategies, Successive Dialogues, Teaching by Projects.

\section{INTRODUÇÃO}

Educação, Psicologia e Interfaces, Volume 4, Número 3, p. 1-11, Julho/Setembro, 2020.

ISSN: 2594-5343. DOI: 10.37444/issn-2594-5343.v4i3.81 
Com a constante transformação do mundo globalizado e a incessante busca por permanecer atualizado nas novidades tecnológicas, além da inserção de termos e conceitos advindos de línguas estrangeiras - mais especificamente do Inglês - na vida cotidiana, somado a procura por cursos livres de Língua Inglesa, fizeram com que as escolas de ensino regular buscassem atualização também em seus currículos.

Segundo os PCNs (BRASIL, 2010, p. 93) "ao se apropriar de uma língua, o aluno se apropria também dos bens culturais que ela engloba. Tais bens lhe permitirão acesso à informação em sentido amplo, bem como uma inserção social mais qualificada, da qual poderá beneficiar-se e sobre a qual poderá interferir". De certa forma, o Inglês passa a fazer parte da vida das pessoas, sem nem mesmo que elas percebam. Está no refrigerante que elas tomam, nos filmes que assistem, no video game, nas roupas que vestem, ou mesmo nas palavras que se tornam jargões, especialmente na comunidade jovem.

Berbel (2011) afirma que a escola tem papel de profundo desenvolvedor e ativador do desenvolvimento gerado pelas, cada vez mais intensas, ações de pensar, sentir e agir diante da complexidade de questões cotidianas enfrentadas pelas pessoas atualmente. Lowman (2004), porém, afirma que o verdadeiro aprendizado ocorre fora de sala de aula, desenvolvido pela leitura, resolução de questões feitas de forma solitária, ainda que se precise ir às aulas para obtenção de conteúdo. Acredita-se que ir à escola envolve um processo não só de apropriação de conteúdos técnicos e de fórmulas e conceitos, mas que ela desempenha um papel importante como o de ativador social, promovedor de interação e crescimento do pensamento crítico, do pessoal e do profissional do cidadão. Desta forma, o uso de estratégias dentro e fora de sala de aula são de suma importância para o processo de ensino e aprendizagem.

Por esta razão, a disciplina de língua inglesa se tornou imprescindível, principalmente para o curso técnico em Comércio Exterior, alvo de observação e discussão deste estudo. Desta forma, foram apresentadas duas propostas de atividades para estimular o interesse pela disciplina e melhoria na qualidade de ensino.

As atividades desenvolvidas durante este estudo se basearam nas ideias apresentadas no livro Competência pedagógica do professor universitário de Masetto (2003), caracterizadas como:

1. Diálogos Sucessivos:

Educação, Psicologia e Interfaces, Volume 4, Número 3, p. 1-10, Julho/Setembro, 2020.

ISSN: 2594-5343. DOI: 10.37444/issn-2594-5343.v4i3.81 
Diálogos sucessivos e ensino por projeto: análise comparativa de estratégias de ensino nas aulas de língua inglesa

Organiza-se a classe em dois círculos concêntricos: metade dos alunos na parte de fora, outra metade, na parte interna voltados uns para os outros (de frente um para o outro) formando pares. Dado um tema, os elementos de fora e de dentro tem aspectos diferentes sobre os quais vão dialogar por um espaço de três a quatro minutos. Terminado esse tempo, os elementos de dentro do círculo giram no sentido anti-horário e se encontram com um segundo elemento. Os elementos do lado de fora permanecem em seus lugares. No segundo encontro cada um expõe ao outro seu aspecto do tema e o aspecto que ouviu do seu par no momento anterior, e ouve o aspecto de seu novo parceiro e o que ele ouviu de seu par anterior. E assim por diante, por umas três ou quatro vezes.

O movimento leva a um conhecimento cumulativo e/ou formas melhores de se expressar a mesma idéia (MASETTO, 2003, p. 117).

O autor explica que esta técnica pode ser aplicada com turmas grandes ou pequenas, aumentando a chance e a quantidade de interação entre os colegas.

2. Ensino por Projetos:

O objetivo do ensino por projeto é criar condições para que o aluno aprenda a propor o encaminhamento e desenvolvimento de determinada situação, partindo de uma análise diagnóstica; indicando os objetivos a serem atingidos (situação ideal futura), as etapas de realização do projeto, e para cada uma delas estabelecendo metas parciais, tempo, participantes, ações, responsabilidades, recursos, estratégias; organizando um sistema de acompanhamento de avaliação e feedback; de tal forma que a realização e interação das várias etapas apresentem o projeto concluído (MASETTO, 2003, p. 106).

Ainda segundo o autor, esta estratégia também tem o objetivo de promover a relação da teoria com a prática, das disciplinas entre si para a interação interdisciplinar, de nível de dificuldade simples ou complexo, condizente com a realidade profissional (um dos objetivos do ensino técnico).

A finalização dessa atividade deverá contar com a apresentação dos projetos para toda a turma, com debate sobre cada um deles, para que todos possam aproveitar dos trabalhos realizados por cada grupo ou aluno e desenvolver assim suas aprendizagens. A apresentação também é um momento de aprendizagem e não apenas um encerramento de trabalhos (MASETTO, 2003, p. 107).

A primeira atividade foi proposta no primeiro dia de aula para a turma de $1^{\circ}$ ano do Ensino Médio integrado ao técnico do já referido curso. Tais atividades objetivaram a interação entre os alunos de mesma turma e com os alunos já veteranos do $2^{\circ}$ ano, bem como a triagem de informações mais relevantes sobre o curso e a instituição em si.

Educação, Psicologia e Interfaces, Volume 4, Número 3, p. 1-11, Julho/Setembro, 2020.

ISSN: 2594-5343. DOI: $10.37444 /$ issn-2594-5343.v4i3.81 
A segunda atividade foi proposta no final do período de avaliações do primeiro bimestre, como forma de projeto a ser aplicado dentro e fora de sala de aula, caracterizado com pesquisa referencial e elaboração de uma mostra cultural, envolveu também, alunos de $1^{\circ}$ ano dos cursos de Marketing, Logística e Publicidade.

\section{MATERIAIS E MÉTODOS}

Como dito anteriormente as atividades propostas foram Diálogos Sucessivos e Ensino por Projeto, que foram desenvolvidas da seguinte forma:

1. Diálogos Sucessivos:

$\checkmark$ Turma: $1^{\circ}$ ano do Ensino médio integrado ao Técnico do Curso de Comércio Exterior.

$\checkmark$ Participantes: turma mista de meninos e meninas com faixa etária de 15 a 16 anos (42 alunos).

$\checkmark$ Data: 13 de fevereiro de 2017, turno da manhã (primeiro dia de aula).

$\checkmark$ Participação convidada: Turma do $2^{\circ}$ ano do Ensino médio integrado ao Técnico do Curso de Comércio Exterior (30 alunos).

$\checkmark$ Duração: 60 minutos.

$\checkmark$ Local: Hall de entrada do Instituto Federal do Amapá - campus Santana.

$\checkmark$ Professores participantes: Professor de Comércio Exterior e então coordenador do curso, professora de língua inglesa, professora de língua francesa, professor de sociologia, professor de geografia e coordenador de ensino naquele momento.

$\checkmark$ Desenvolvimento da atividade:

Foi solicitado aos alunos do $2^{\circ}$ ano que fizessem um círculo e aos alunos do $1^{\circ}$ ano que formassem um círculo externo e maior. Como a quantidade de alunos do $1^{\mathrm{o}}$ ano era 
Diálogos sucessivos e ensino por projeto: análise comparativa de estratégias de ensino nas aulas de língua inglesa

maior que a do $2^{\circ}$, alguns aguardaram nas proximidades. Os demais que estavam no círculo foram instruídos a se sentar no chão, frente ao seu par da outra turma.

Nestes círculos, ambas as turmas se apresentaram de forma rápida. Os alunos do segundo ano passaram informações relacionadas ao curso, às disciplinas, aos projetos, trabalhos e professores, além das vantagens e desvantagens de adentrar no IF. Por sua vez, os alunos do $1^{\circ}$ ano buscaram por mais informações.

Devido ao tempo da aula e a quantidade de alunos, o tempo de conversa entre os pares foi estipulado e cronometrado para um minuto. Após esse tempo, os alunos do círculo externo ( $1^{\circ}$ ano), deveriam girar e passar a conversar com o colega seguinte, no sentido horário. Depois de um certo tempo, alguns alunos do $1^{\circ}$ ano foram retirados do círculo para que os que ficaram de fora pudessem entrar e continuar o processo.

2. Ensino por Projetos:

$\checkmark$ Turma: $1^{\circ}$ ano do Ensino médio integrado ao Técnico do Curso de Comércio Exterior.

Participantes: turma mista de meninos e meninas com faixa etária de 15 a 16 anos (42 alunos).

$\checkmark$ Data: 17.04 (sala de aula); 24.04 (sala de aula); 05.05 (área de convivência do campus).

Demais participantes: Turma do $1^{\circ}$ ano de logística (50 alunos), Marketing (48 alunos), Publicidade (40 alunos); total de 180 alunos apresentando trabalhos, mais cerca de 50 alunos dos $2^{\circ}$ anos que prestigiaram o evento.

$\checkmark$ Duração: 2h/aula (sala de aula); 4 horas (mostra cultural), totalizando 8 horas de presença na instituição, mais horas semanais de planejamento extraclasse.

$\checkmark$ Local: área de convivência do Instituto Federal do Amapá - campus Santana.

Educação, Psicologia e Interfaces, Volume 4, Número 3, p. 1-11, Julho/Setembro, 2020.

ISSN: 2594-5343. DOI: $10.37444 /$ issn-2594-5343.v4i3.81 
Equipe de apoio: Curso Técnico em Comércio Exterior, modalidade subsequente (10 alunos).

\section{$\checkmark$ Desenvolvimento da atividade:}

No dia 03 de abril, em sala de aula, os alunos foram instruídos sobre o projeto que consistia da seguinte metodologia:

A divisão dos grupos ocorreu da seguinte forma:

\begin{tabular}{|l|c|c|}
\hline \multicolumn{1}{|c|}{ TEMA } & INGLATERRA & ESTADOS UNIDOS \\
\hline Culinária & Grupo 1 & Grupo 5 \\
\hline Pontos & Grupo 2 & Grupo 6 \\
\hline Música & Grupo 3 & Grupo 7 \\
\hline Grupo 4 & Grupo 8 \\
\hline
\end{tabular}

Obs. 1: as outras turmas foram divididas da mesma forma, com os mesmos temas, mas com países diferentes.

Obs. 2: Todos os países relatados são falantes da Língua Inglesa, como Canadá, Irlanda, Austrália, Jamaica, Republica Dominicana e Nova Zelândia.

Após pesquisa referencial, nos dias 17 e 24 de abril os alunos apresentaram seus temas em sala de aula, sendo avaliados sob os critérios de informações relevantes, forma de apresentação, postura, criatividade e comprometimento. Depois de todas as apresentações, os grupos 1, 2, 3 e 4, que falariam sobre a Inglaterra, por exemplo, uniramse para planejar a mostra cultural. O mesmo aconteceu com os grupos dos Estados Unidos assim como nas outras turmas também, de forma que durante o evento houvesse apenas oito países.

Os alunos se organizaram e apresentaram um prato típico de cada país, estudado e apresentado anteriormente em sala de aula, bem como uma dança ou música típica do lugar. No dia 05 de maio, dia do evento, cada grupo de cada país organizou seu próprio espaço, ornamentando da forma que desejassem. Para isso, precisaram montar um plano de ação, com custo dos materiais utilizados, quem ficaria responsável por cada função, bem como a preparação do prato típico e seu custo, pois precisaram trazer em grande quantidade, de forma que a iguaria servisse de moeda de troca para a degustação dos demais grupos. 
Diálogos sucessivos e ensino por projeto: análise comparativa de estratégias de ensino nas aulas de língua inglesa

\section{RESULTADOS E DISCUSSÃO}

Na estratégia de Diálogos Sucessivos, após ter completado o giro, os alunos puderam se levantar e foram convidados a expor suas impressões relacionadas ao que ouviram dos demais colegas. Os que se pronunciaram, relataram que o curso seria difícil devido à grande carga horária, mas que teriam ótimos professores e que o incentivo a projetos culturais e acadêmicos seria grande, o que os interessou bastante. Alguns relataram sobre a importância das línguas estrangeiras no decorrer do curso, bem como de outras disciplinas.

Os alunos do $2^{\circ}$ ano também se pronunciaram, e como já tinham certa experiência com curso, disseram que seria imprescindível que a turma nova se unisse nas dificuldades e tentassem ajudar um ao outro, tornando o vínculo social e afetivo entre eles bem maior, para que conseguissem lidar com a nova fase e nova jornada de estudo. A turma também se colocou à disposição para ajudar no que fosse necessário.

Por se tratar do primeiro dia de aula e muitos ainda não se conheciam, os alunos ficaram muito acanhados, não queriam participar, nem se pronunciar quando foi solicitado. Mas, à medida em que iam conversando com seus pares do $2^{\circ}$ ano, conseguiram interagir e sanar algumas dúvidas.

Alguns relatos dos alunos e professores (quadro 1), proporciona maior esclarecimento sobre o que a atividade representou. Vale ressaltar que as falas não foram transcritas, mas foram retirados os pontos principais para utilização neste estudo.

Quadro 1:

\begin{tabular}{cl} 
PARTICIPANTE & \multicolumn{1}{c}{ RELATO } \\
$\begin{array}{c}\text { Professora de Língua } \\
\text { Francesa }\end{array}$ & $\begin{array}{l}\text { O que é interessante é que eles não estão só conversando sobre } \\
\text { banalidades e sim sobre o curso e sobre as disciplinas. O foco } \\
\text { está inteiramente na proposta da atividade. }\end{array}$ \\
& Sei que vocês ficaram muito empolgados, principalmente com a \\
& notícia dos jogos e a possibilidade de poder viajar e representar \\
o Instituto, porém, é preciso que vocês foquem nos estudos. Pois \\
Professor de Geografia \\
o aluno que se destacar nos jogos, mas não estiver bem em sala \\
de aula e nas suas notas, não será agraciado com a viagem. O \\
principal foco e objetivo de vocês aqui deve ser o estudo.
\end{tabular}

Educação, Psicologia e Interfaces, Volume 4, Número 3, p. 1-11, Julho/Setembro, 2020.

ISSN: 2594-5343. DOI: $10.37444 /$ issn-2594-5343.v4i3.81 


\begin{tabular}{|c|c|}
\hline Aluno $A\left(1^{\circ}\right.$ ano $)$ & $\begin{array}{l}\text { Conversando com os colegas, percebi que é um curso muito } \\
\text { difícil, mas também muito interessante. }\end{array}$ \\
\hline Aluno B ( $1^{\circ}$ ano $)$ & $\begin{array}{l}\text { Os colegas me informaram que estudar no IFAP não é para } \\
\text { muitos, tem que se dedicar. }\end{array}$ \\
\hline Aluno C ( $1^{\circ}$ ano $)$ & $\begin{array}{l}\text { Eu gostei quando disseram que podemos viajar para outros } \\
\text { estados durante os jogos internos e olimpíadas. }\end{array}$ \\
\hline Aluno D ( $2^{\circ}$ ano $)$ & $\begin{array}{l}\text { O mais importante é que vocês sejam unidos, só assim } \\
\text { conseguirão até o fim. Se mostrarem união e se ajudarem, as } \\
\text { disciplinas ficam mais fáceis. Um colega que entendeu o } \\
\text { conteúdo, pode repassar de uma maneira diferente da que o } \\
\text { professor estava explicando. }\end{array}$ \\
\hline Aluno E ( $1^{\circ}$ ano $)$ & $\begin{array}{l}\text { Percebi que nesse curso vou ter contato com muitas línguas } \\
\text { estrangeiras e os colegas disseram que os professores são muito } \\
\text { bons. }\end{array}$ \\
\hline
\end{tabular}

Já na estratégia de Ensino por Projetos foi possível analisar o envolvimento dos participantes em um trabalho em equipe, quando organizaram inclusive a limpeza do local após o evento, além de promover a interação social com os próprios colegas de classe, com os das outras turmas de $1^{\circ}$ ano e das turmas de $2^{\circ}$ ano que atuaram apenas como expectadores no evento. Mais ainda, o evento proporcionou, de forma lúdica, o conhecimento de novas culturas, novos países falantes da língua inglesa, seus costumes e como se parecem com os costumes que se tem no Brasil.

Ao final do projeto, os grupos apresentaram um relatório, indicando a função e participação de cada integrante do grupo. Vale ressaltar também que o evento se tornou integrante de um projeto macro de extensão desenvolvido pela instituição, garantindo aos alunos a emissão de certificados com carga horária válida. Um vídeo do evento foi produzido, voluntariamente, por um dos alunos e pode ser encontrado no endereço https://www.facebook.com/gustavo.lazame/videos/968153659994369/

Nesta estratégia, foi perceptível a dificuldade dos alunos para trabalhar em equipes, pois alguns não produziram durante a apresentação em sala de aula ou compareceram durante a mostra cultural, resultando na perda dos créditos necessários para aprovação no primeiro bimestre do ano.

Educação, Psicologia e Interfaces, Volume 4, Número 3, p. 1-10, Julho/Setembro, 2020. ISSN: 2594-5343. DOI: 10.37444/issn-2594-5343.v4i3.81 
Diálogos sucessivos e ensino por projeto: análise comparativa de estratégias de ensino nas aulas de língua inglesa

Muitos alunos solicitaram ajuda para resolver pequenos conflitos dentro dos grupos, por não conseguirem lidar com opiniões contrárias. O resultado destes conflitos foi que alguns alunos acabaram saindo de seus grupos de origem e passaram a trabalhar com grupos até mesmo de outras turmas. Alguns alunos do $2^{\circ}$ ano, até então expectadores, participaram das apresentações musicais de alguns grupos do $1^{\circ}$ ano. O que demonstrou tamanho interesse pelo trabalho e espirito de participação.

Muitas queixas surgiram por parte dos alunado do $2^{\circ}$ ano com relação à forma como o trabalho foi produzido, pois se sentiram enciumados por não poderem desenvolver um trabalho parecido, especialmente no ano anterior (quando estavam no $1^{\circ}$ ano). Pois também queriam desenvolver sua própria mostra cultural.

\section{CONSIDERAÇÕES FINAIS}

Ambas as atividades foram avaliadas de forma positiva, mesmo apresentando algumas dificuldades no decorrer do processo. A primeira de forma menor, pois se tratava de uma atividade mais simples, que não requeria necessidade de material de apoio, apenas o material humano já citado anteriormente. A segunda precisou de um planejamento logístico maior, haja vista a quantidade de participantes, além do material de consumo necessário da instituição (projetor, caixa de som, carteiras, etc.) e do material para ornamentação e produção das atividades (balões, enfeites e as comidas para degustação). Mesmo assim, o evento aconteceu e foi considerado excelente pelos mais de 150 alunos envolvidos. Gratificando a todos, especialmente a equipe organizadora.

\section{REFERÊNCIAS}

BRASIL. Orientações Educacionais Complementares aos Parâmetros Curriculares Nacionais. 2010. Disponível em

<http://portal.mec.gov.br/seb/arquivos/pdf/linguagens02.pdf>. Acesso em: 20 Jan 2017.

BERBEL, Neusi Aparecida Navas. As metodologias e a promoção da autonomia de estudantes. Revista Semina: Ciências Sociais e Humanas, Londrina, Paraná, v. 32, n. 1, p. 25-40, jan/jun. 2011. Disponível em:

<http://www.uel.br/revistas/uel/index.php/seminasoc/article/view/10326>. Acesso em: 30 abril 2017.

LOWMAN, Joseph. Dominando as técnicas de ensino. São Paulo: Atlas, 2004. cap.8. Disponivel em:

Educação, Psicologia e Interfaces, Volume 4, Número 3, p. 1-11, Julho/Setembro, 2020.

ISSN: 2594-5343. DOI: $10.37444 /$ issn-2594-5343.v4i3.81 
<https://www.univates.br/virtual/pluginfile.php/869236/mod_resource/content/0/Lowm an_2004_cap_8.pdf >. Acesso em: 30 abril 2017.

MASETTO, Marcos Tarciso. Competência pedagógica do professor universitário.

São Paulo: Summus, 2003. p. 85-139. Disponível em:

$<$ https://www.univates.br/virtual/pluginfile.php/869230/mod_resource/content/0/Texto_ masetto.pdf >. Acesso em: Acesso em: 30 abril 2017.

Mostra Cultural. Produção: Gustavo Lazamé Rodrigues. Santana, 2017. Disponível em <https://www.facebook.com/gustavo.lazame/videos/968153659994369/>. Acesso em: 17 maio 2017.

\section{Credenciais das autoras}

GRANGEIRO, Letícia Maria dos Santos. IFAP, Campus Santana, AP - Brasil. E-mail: leticiagrangeiro@hotmail.com

PINO, José Claudio Del. UNIVATES, Lajeado, RS - Brasil. E-mail: jose.pino@univates.br

QUARTIERI, Marli Teresinha. UNIVATES, Lajeado, RS - Brasil. E-mail: mtquartieri@univates.br

MARCHI, Miriam Inês. UNIVATES, Lajeado, RS - Brasil. E-mail: mimarchi@univates.br

Endereço para correspondência: Letícia Maria dos Santos Grangeiro. E-mail: leticiagrangeiro@hotmail.com

GRANGEIRO, Letícia Maria dos Santos et al. Diálogos sucessivos e ensino por projeto: análise comparativa de estratégias de ensino nas aulas de língua inglesa. Educação, Psicologia e Interfaces, v. 4, n.2, p. 1-10, 2020.

Recebido: 04/04/2020.

Aceito: 20/05/2020. 